\title{
The Histopathology of Tongue Lesions in Leprosy
}

\author{
A. MUKHERJEE, B. K. GIRDHAR and K. V. DESIKAN \\ Central JALMA Institute for Leprosy, \\ Taj Ganj, Agra-282001, India
}

\begin{abstract}
A histopathological study of the tongue lesions in 8 cases of lepromatous leprosy is presented. The salient histopathological changes in these lesions are described and the implication of the findings discussed.
\end{abstract}

\section{Introduction}

Involvement of the oral cavity in cases of lepromatous leprosy is well known (Dharmendra, 1967; Cochrane, 1964). The various structures in the oral cavity commonly affected are the gums, the hard and soft palates, the uvula and the tongue (Reichart, 1976). Although clinical descriptions of these are available (Reichart, 1976; Lighterman, 1962), reports of the histopathology of these lesions, however, are very few (Ishihara, 1975; Reichart, 1974).

The present report describes the histopathological changes seen in the tongue lesions of lepromatous leprosy.

\section{Material and Methods}

Eight patients were biopsied for the purpose of the study. All of them were patients with lepromatous leprosy. Six of them had disease of more than 10 years' duration, while the other 2 had a shorter duration of 7 and 2 years respectively. Three patients had taken dapsone irregularly for varying periods of 2 to 4 years. The others had not received any treatment.

Gross lesions were present on the tongue in all 8 cases but none had any symptoms attributable to its involvement. Tests for sensation of touch and taste were not performed. One patient had large nodules $(1 \mathrm{~cm}$ diameter $)$ on the dorsum of the tongue which were separated by deep fissures giving a "cobble-stone" appearance. Two had diffusely scattered small papules more on the anterior two-thirds of the tongue. Three had solitary nodules over the tip of the tongue, one of them showing atrophic scarring in addition. Two patients had diff use thickening of the tongue, one of them with loss of papillac as well.

Biopsies of tongue lesions were performed under local anaesthesia. The tissues were fixed in Formol-Zenker for $24 \mathrm{~h}$, processed, embedded in paraffin 


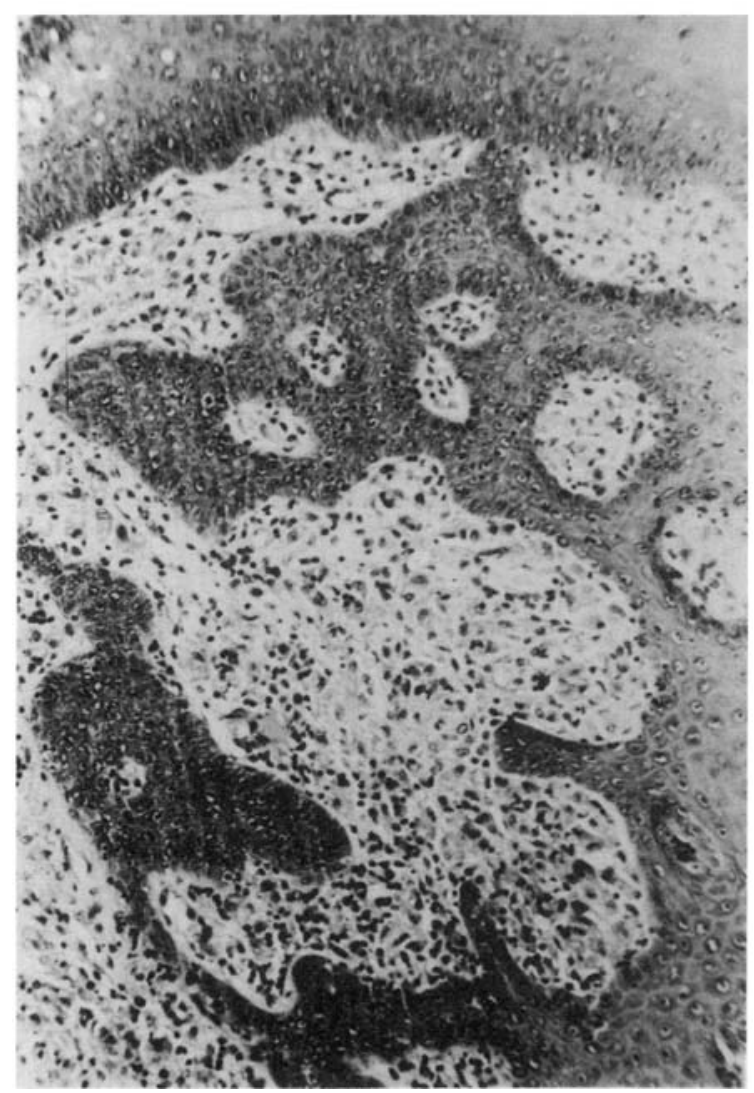

Fig. 1. Tongue lesions in lepromatous leprosy showing epithelial hyperplasia. H \& E. $\times 100$.

and 5 - $\mu$ m-thick sections were cut and stained with $\mathrm{H} \& \mathrm{E}$, Fite's modification of Ziehl-Neelsen's stain and Picro-Mallory's stain.

\section{Results}

All the 8 biopsies showed lepromatous granulomata histologically. The histological findings are described below.

\section{EPITHELIUM}

In all 8 cases, the epithelium was continuous and no ulcerations were seen. Four cases showed evidence of mild to moderate epithelial hyperplasia (Fig. 1). No epithelial dysplasia was observed. Of the rest, 3 had normal epithelium while only one showed flattening of the epithelium.

The inflammatory infiltrate extended into the epithelium in one case. In this 


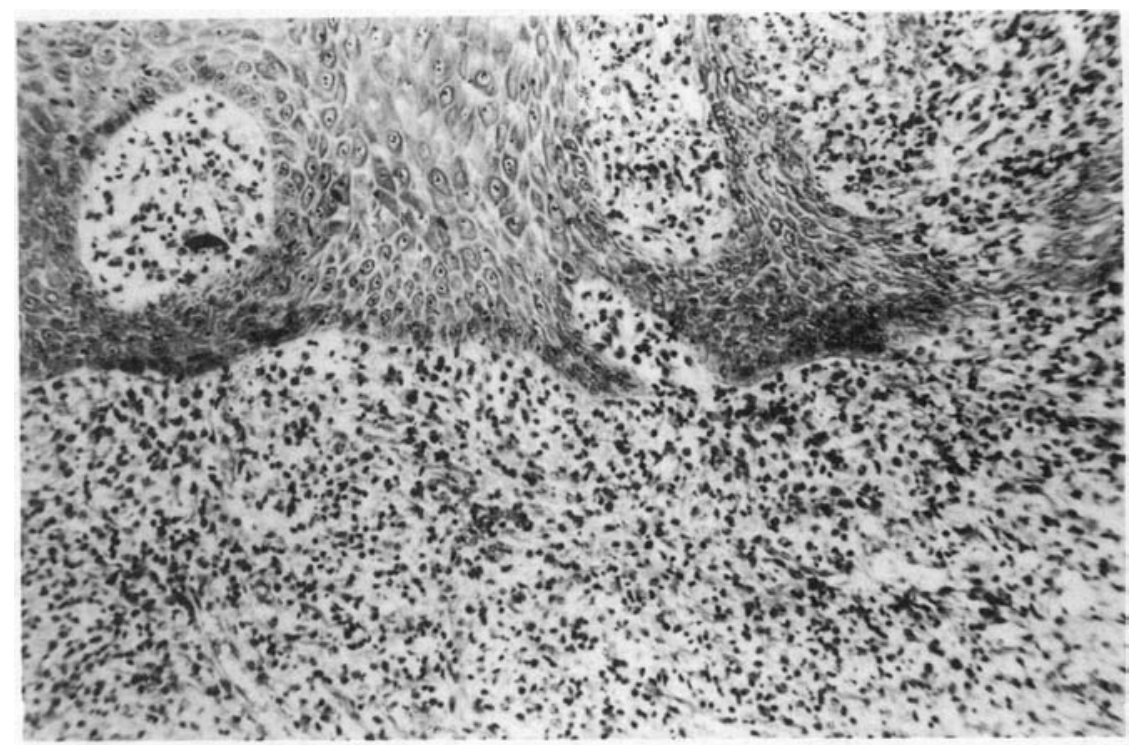

Fig. 2. Lepromatous granuloma of tongue showing extension up to basal layer of epithelium encroaching on the sub-epithelial zone. H \& E. $\times 100$.

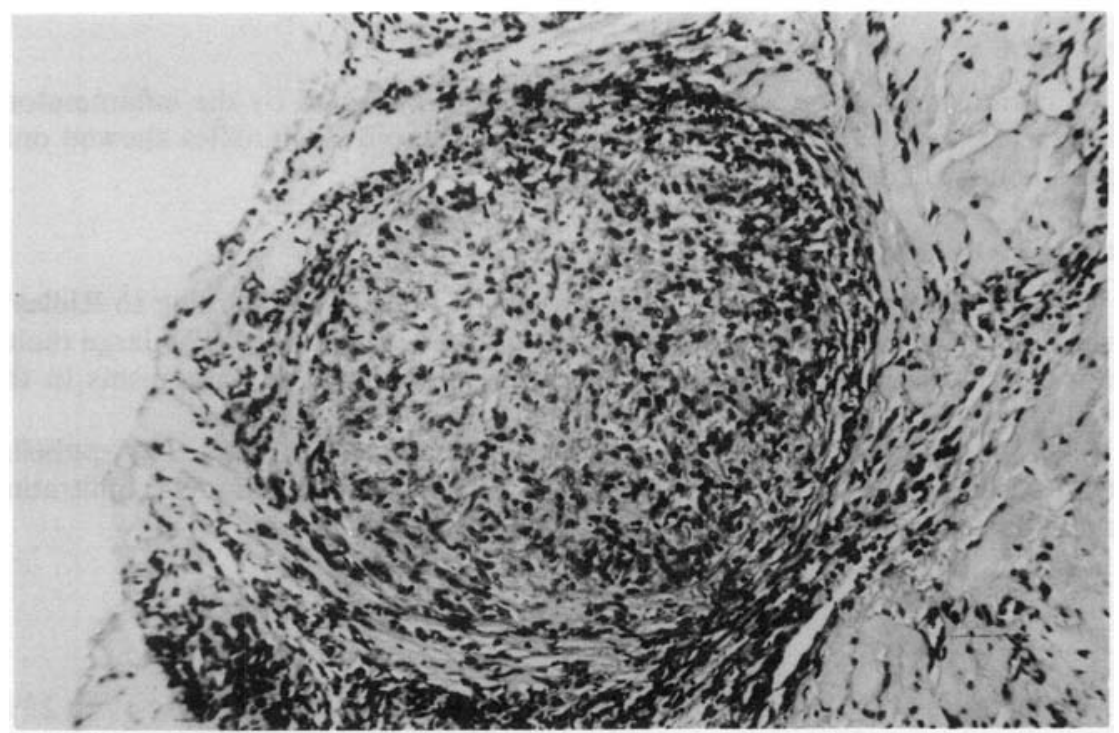

Fig. 3. A nerve in the tongue showing infiltration and destruction. H \& E. $\times 400$. 
the epithelium was thin at some places while in other places long proliferating rete pegs were seen. The picture suggested the edge of an ulcerating lesion.

\section{SUB-EPITHELIAL ZONE}

None of the cases with diffuse infiltration showed any evidence of a clear sub-epithelial zone as seen in the skin lesions of lepromatous leprosy. In all cases the granuloma extended right up to the basal layers (Fig. 2).

\section{SUB-EPITHELIAL TISSUES}

Extensive lepromatous granulomata composed of sheets of macrophages were seen in 5 cases. One case had an irregularly branching granuloma whilst the remaining 2 had only slight to moderate patchy granulomatous infiltration of the sub-epithelial layers.

The infiltrate in all the cases was richly vascular. It comprised mainly of vacuolated and non-vacuolated macrophages, scant to moderate numbers of plasma cells, lymphocytes and occasional polymorphs.

\section{NERVES}

Nerve twigs could be identified in 4 cases. In all the 4 they were infiltrated by exudate cells. In 2 of these cases, the nerves were found in the midst of a large granuloma. Here the nerve showed lamination, infiltration by foam cells and destruction (Fig. 3). In the other 2 cases, the cellular infiltration was patchy and mainly around the nerves. One of these cases also showed large multi-nucleated foamy giant cells with large single vacuoles in the neurovascular bundles.

\section{MUSCLE}

The muscular tissues were compressed and infiltrated by the inflammatory infiltrates (Fig. 4). In the cases with less infiltration, the bundles showed only mild non-specific changes.

\section{BACILLARY POPULATION}

The bacillary content could be graded as $4+$ to $6 \frac{1}{2}+$ according to Ridley's scale (Fig. 5). Bacilli were found in macrophages and nerves. The large multinucleated cells seen in one case contained several broken organisms in the vacuoles.

The muscle fibres were not found to contain any organisms. The epithelial layers were devoid of bacilli except in one case where the histiocytes infiltrating these layers contained some organisms.

\section{Discussion}

Reichart (1976) has reported that the tongue is involved in about 17 to $25 \%$ of cases of lepromatous leprosy. Since the literature on this subject is sparse, 


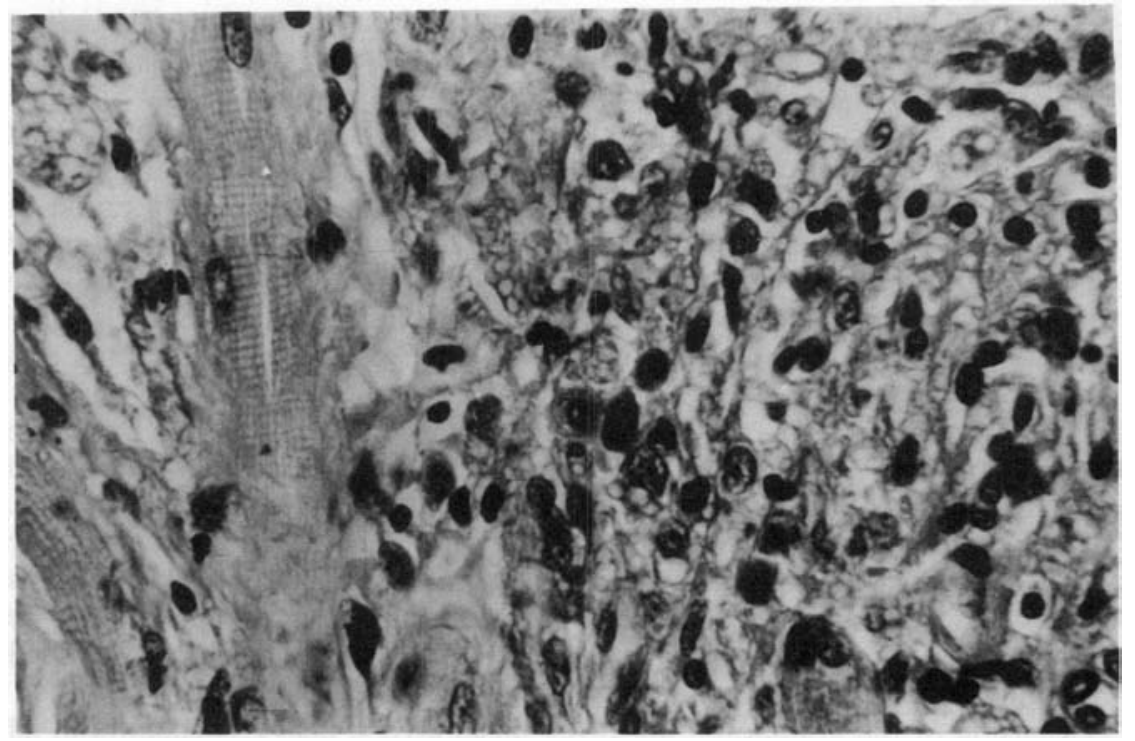

Fig. 4. Lepromatous granuloma showing infiltration of cells in between muscle bundles. H \& E. $\times 400$.

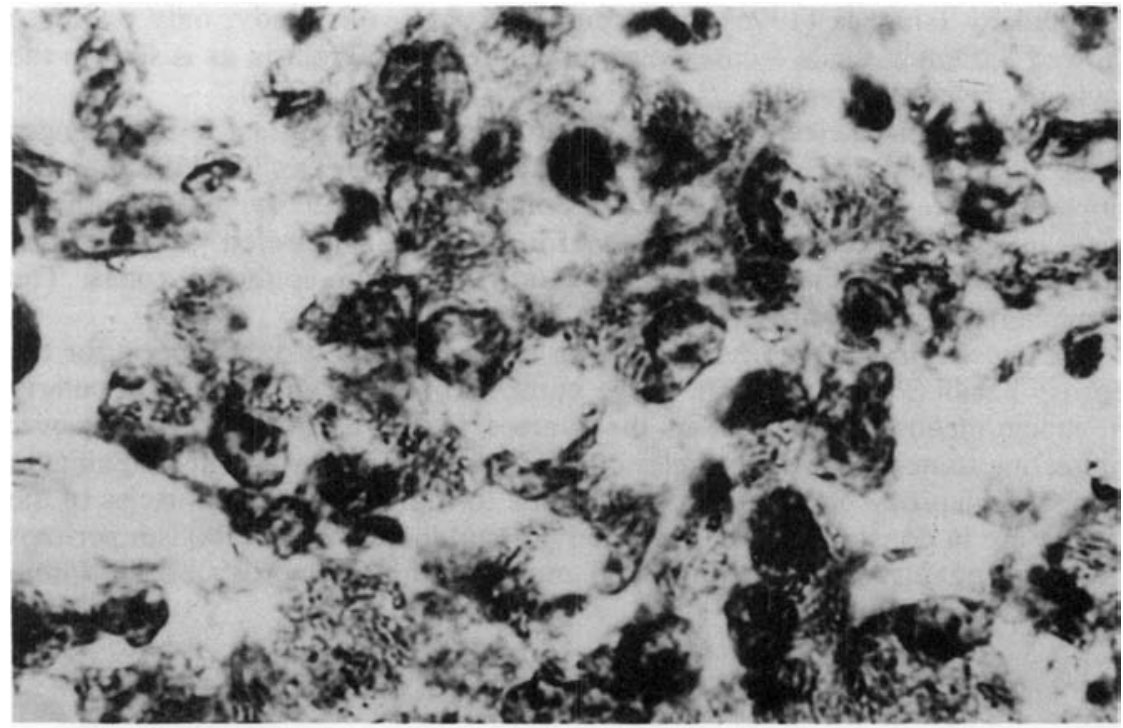

Fig. 5. Microphotograph showing the heavy bacillary population present in the lesion. Fite's stain. $\times 1000$. 
details of the pattern of microscopic involvement are still not clear. The salient features of the tongue lesions as observed in this study are: (i) all the cases which showed clinical evidence of tongue involvement had definite histopathological lesions of leprosy; (ii) the composition of the infiltrate and the pattern of the granuloma was similar to that seen in skin lesions; (iii) the sub-epithelial zone was encroached in all cases with a heavy infiltration of exudate cells; (iv) nerves were preferentially affected; (v) the epithelium showed hyperplasia; (vi) all the lesions were heavily bacillated; (vii) the muscles were compressed or infiltrated by the granuloma but bacilli were not seen in large numbers as is found in muscles similarly located elsewhere e.g. Dartos and Arrectores Pilorum etc.

These findings lead to certain important considerations. Extensive involvement of the nerve twigs as seen even in the relatively less infiltrated lesions could well lead to sensory and/or motor loss of function of the tongue. These functions, unfortunately, were not tested in the present study. Earlier studies also do not mention any loss of taste function. Reichart (1974) in his study of the soft palate in leprosy has found motor impairment to be associated with infiltration in the palate. However, he has not described destruction of the nerves histologically in these cases.

Extension of the granuloma up to the basal layers, heavy bacillation in all cases and presence of bacilli-laden histocytes in the epidermis strongly suggest that the leprosy bacilli from the lesions of the tongue could easily be extruded into the mouth secretions and discharged through the saliva while spitting.

The epithelial changes are in contrast to that seen in the skin lesions of lepromatous leprosy. Atrophy and flattening is the normal reaction of the epidermis in skin lesions. Flattening of the epithelium of the tongue is also reported by Ishihara (1975) in his case report. In this study, only one case showed flattening while 4 cases showed epithelial hyperplasia as is seen in the epidermis over the granulomas in tuberculosis (Nirmala, 1977).

The absence of a clear sub-epithelial zone is also in contrast to the changes in the skin. In autopsy studies on lepromatous patients (Desikan, 1968) and in biopsy specimens of oral and palatal lesions (Reichart, 1974) the sub-epithelial zone in the larynx and palate was found to be infiltrated. Conjunctival lepromatous lesions also fail to show any clear sub-epithelial zones. The significance of this finding is however still not clear.

The muscle has been described as an important site of predilection for the leprosy bacilli (Pearson, 1970). Large numbers of bacilli are found particularly in subcutaneous muscles as in the Dartos (Pandya, 1974). It is however interesting to note that the muscles of the tongue do not exhibit any significant number of leprosy bacilli. This may be due to the fact that the muscles of the tongue are in constant action, their activity and increased metabolism perhaps militating against the lodgement and multiplication of leprosy bacilli within them.

\section{References}

Cochrane, R. G. (1974). In Leprosy in Theory and Practice, pp. 322. Cochrane, R. G. and Davey, T. F., Eds. John Wright \& Sons Ltd, Bristol. 
Desikan, K. V. and Job, C. K. (1968). A review of post-mortem findings in 37 cases of leprosy. Int. J. Lepr. 36, 32.

Dharmendra (1967). Notes on leprosy published by Ministry of Health, Government of India, pp. 46.

Ishihara, S. (1975). A case report on leproma in the tongue. La lepro. 44, 199 [reprinted in Lepr. India (1977) 49, 419].

Lighterman, I., Watanabe, Y. and Hidaka, T. (1962). Leprosy of the oral cavity and adnexa. Oral Surg. 15, 1178.

Nirmala, V., Chacko, C. J. G. and Job, C. K. (1977). Tuberculoid leprosy and tuberculosis skin - a comparative histopathological study. Lepr. India 49, 65.

Pandya, N. J. and Antia, N. H. (1974). The value of scrotal biopsy in leprosy. Lepr. Rev. 45, 145.

Pearson, J. M. H., Rees, R. J. W. and Weddell, A. G. M. (1970). Mycobacterium leprae in the striated muscle of patients with leprosy. Lepr. Rev. 41, 155.

Reichart, P. (1974). Pathologic changes in the soft palate in lepromatous leprosy. Oral Surg. 38, 898.

Reichart, P. (1976). Facial and oral manifestations in leprosy. Oral Surg. 41, 385. 